\title{
"JONAS E O CIRCO SEM LONA": ENTRE O CIRCO E A ESCOLA, OLHAR UMA INFÂNCIA
}

\author{
“JONAS AND THE BACKYARD CIRCUS”: BETWEEN THE CIRCUS AND THE SCHOOL, LOOKING \\ AT A CHILDHOOD
}

(D) https://orid.org/0000-0003-3611-9639 Sara Reis Teixeira ${ }^{\mathrm{A}}$ https://orcid.org/0000-0003-3289-2528 Marcos Ribeiro de Melo ${ }^{\text {B }}$ https://orcid.org/0000-0002-9013-6352 Michele de Freitas Faria de Vasconcelos ${ }^{\mathrm{C}}$

${ }^{\text {A }}$ Universidade Federal de Sergipe (UFS), São Cristóvão, SE, Brasil

${ }^{B}$ Universidade Federal de Sergipe (UFS), São Cristóvão, SE, Brasil

${ }^{\mathrm{C}}$ Universidade Federal de Sergipe (UFS), São Cristóvão, SE, Brasil

Recebido em: 29 nov. $2021 \mid$ Aceito em: 20 jan. 2022
Correspondência: Sara Reis Teixeira (sarareisteixeira@ gmail.com)
Marcos Ribeiro de Melo (marcos_demelo@ hotmail.com)
Michele de Freitas Faria de Vasconcelos (michelevasconcelos@ hotmail.com)

\section{Resumo}

Sabe-se que escola é uma invenção moderna, um projeto de civilização com vistas a homogeneizar o mundo, embranquecendo-o por meio da 'naturalidade' da cultura europeia, de seus modos de conhecer, ver e viver. Mas, a vida sempre vaza: um circo sem lona, no quintal de casa, convida a artistarmos uma escola sem paredes, a outrar a cultura escolar. A proposta é vazar a tela da vida escolarizada/civilizada por meio do encontro com o filme "Jonas e o circo sem lona" (2015), que nos convida a uma desaprendizagem do olhar a infância e a escola, contagiando-a, sem folclorizar ou exotificar, de vida saberes populares, brasileiros e nordestinos. Nesse artigo, foi utilizado o cinema como um campo de produção de dados desenvolvidos a partir de uma etnocartografia de tela. Assim, foi possível transver a infância como um posicionar-se intensivo no mundo em agenciamento com a pluralidade heterogênea de práticas que a compõem.

Palavras-chave: infância; cinema; educação; civilização.

\begin{abstract}
We know that school is a modern invention, a project of civilization with a view to homogenizing the world, whitening it through the 'naturalness' of European culture, its ways of knowing, seeing and living. But life always escapes: a circus in the backyard invites us to habit a school without walls and to change school culture. Our proposal is to overflow the screen of schooled / civilized life with the encounter with the film "Jonas and the backyard circus" (2015), inviting us to unlearn how to look childhood and school, proliferating, without folklorizing or exoticizing, the popular knowledges from Brazil and the Northeast. In this article, we use cinema to produce data with screen ethnocartography. Thus, it was possible to see childhood as an intensive position in the world in assemblage with the heterogeneous plurality of practices that compose it.
\end{abstract}

Keywords: childhood; cinema; education; civilization. 
Meu sonho era ser engenheiro. Queria construir pontes, estradas, castelos. Construí apenas castelos de sonhos para muita gente. Sou, de qualquer maneira, um engenheiro! E, estou feliz por isso!

Lápide do Palhaço Piolin

O que restou agora é uma revolta menos heroica, menos vistosa, menos romanesca talvez. Não estamos apenas limitados a escolher entre a obediência e rebelião. As crianças sabem bem disso, sabem como enfurecer seus pais fazendo birra, arrastando os pés, fingindo, rindo às escondidas.

Patrick Boucheron

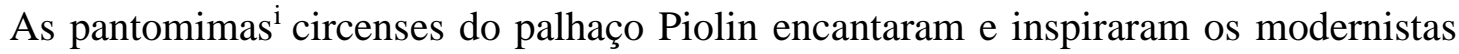
brasileiros. No terceiro número do jornal literário “Terra roxa e outras terras ${ }^{\mathrm{ii}}$ ”, em 1926, Mário de Andrade, sob o pseudônimo de Pau D'alho, elogiava o circo e a revista como os únicos espetáculos cênicos onde a liberdade e a criação se faziam presentes, movidas pelas necessidades artísticas e distante das moralizações absolutas postas em obras clássicas como as de Moliére ou da Divina Comédia, “onde se pratica a justiça premiando os bons e castigando os maus" (ANDRADE, 1926, p. 2). Ao se referir diretamente ao palhaço, o poeta se fez reticente aos elogios e afirmou que era preciso que Piolin permanecesse inconsciente do seu próprio valor e, sobretudo, a indiferença no criar, pois "pra certa ordem de artistas geralmente a perseverança do valor depende da desatenção estética com que inventam. Piolin se quiser conservar o valor extraordinário que possui tem que permanecer o criador desatento que até agora foi” (ANDRADE, 1926, p. 2).

Pode o encontro iii entre cinema, infância e arte circense desencaminhar o projeto civilizatório em curso na escola e colocar sob suspeita o destino por ele traçado? Eis a questão que nos inquieta neste artigo inspirado pelos sonhos de um garoto periférico de 13 anos, no documentário Jonas e o circo sem lona (2015), dirigido pela cineasta Paula Gomes. Dividido entre artistar a vida com o circo e as obrigações escolares, o menino Jonas se equilibra numa corda bamba entre obedecer e desobedecer, viver o presente ou empreender um futuro, ser um palhaço ou um trabalhador (talvez) com carteira assinada ${ }^{\text {iv }}$. Como ampliar a vida diante da cooptação política da educação inclusiva e da promessa de combate à exclusão social erigida por uma governamentalidade democrática (GALLO, 2015) que instrumentaliza como "direito da criança" a obediência (escolar e à escolarização)? 
O cenário se complexifica quando a narrativa fílmica apresenta contornos generificados e racializados que ganham forma, por um lado, na imagem do menino negro, pobre e vulnerável de Jonas e, por outro lado, na figura de sua mãe, que irrompe as cenas mostrando sua dedicação e resignação ao seu papel de salvadora ${ }^{\mathrm{v}}$. Jonas é um garoto baiano de 13 anos que cultiva um circo no quintal da casa de sua avó. Toda sua família é circense: sua mãe e sua avó participavam de espetáculos desde pequenas e seu tio comanda o circo da família do qual Jonas também quer ser parte. Em todos, o sentimento do circo vive, realizando-se de algum jeito. Sua mãe, no entanto, desaprova a paixão do menino pelo picadeiro, pois crê que "os tempos mudaram", que o circo não é o melhor caminho para Jonas, o qual deve permanecer na escola e se dedicar aos estudos, como promessa de uma vida menos incerta. Em meio a essas questões, as câmeras encontram-se com Jonas e tecem imagens-experiências de infância.

Pensar no cinema enquanto espaço de experimentação e invenção de si e de mundos é apostar que a arte não imita a vida, nem o seu avesso. Há na articulação entre cinema e infância o emergir de pluralidades enunciativas ${ }^{\mathrm{vi}}$ que falam com a infância, expondo visibilidades e dizibilidades que buscam (des)caminhos em sua força de experiência (KOHAN, 2007). É fazer das redes de saberes curriculares generificados (PARAÍSO, 2011) um trampolim de circo, é pensar os movimentos (im)possíveis de desobediência desse corpo infante cuja "singularidade silenciada não pode ser assimilada pelo sistema” (KOHAN, 2011, p. 239). É tentar, do seio da linguagem que toma as crianças como presos políticos (DELEUZE, 1992), dar língua e corpo aos afetos que pedem passagem (ROLNIK, 2018). É produzir imagens infantis anunciadoras da movência do mundo, da errância da vida.

Em busca da ambição de gente menor ${ }^{\text {vii }}$, também uma ambição menor, parece ser necessário rabiscar modos outros de pensar a infância, ensaiar uma (des)aprendizagem do produzir imagens cultivando um olho cinematográfico (não hollywoodiano). É assim que podemos pensar com Kohan (2007) ao afirmar a infância como um devir, o pensar que se faz entre o possível e o impossível, tempo-infância que se realiza em suas próprias construções experimentais e é dotado de uma força-outra, aquela que faz do corpo infantil palco para encontros, e não tábula de inscrição. Também para isso urge a problematização das forças (saberes e poderes) que desembocam nos fazeres pedagógicos dos currículos escolares, embebidos por uma historicidade criadora de uma infância faltante (em fase de desenvolvimento, em que o fim é a adultez civilizada), infância incapaz a ser sempre guiada, tutelada e cuidada pela família, pela escola, pela nação, pelos médicos (HECKERT, 2018) e, assim, destituída de sua potencialidade. 
Para instalar essa experimentação conceitual-metodológica-imagética, semeamos uma atenção flutuante, cartográfica, no acompanhamento de processos gerados nesses encontros com a tela, no sentido da "produção do que, em alguma medida, já estava lá de modo virtual" (KASTRUP, 2007, p. 15); do mergulho num tempo entendido não como historicização, descrição de marcar do passado, mas de uma imersão no "tempo da criação, do ilimitado ainda por vir, que, entretanto, já nos habita como uma espécie de futuro anterior" (FONSECA, 2007, p. 142). Nessa direção, aceita-se o espelho da descrição do que somos e do mundo em que habitamos apenas como dispositivo de luta contra o nosso presente. $\mathrm{O}$ adubar dessa atitude de pesquisa-enxada, a arar as terras do presente, revolvendo-lhe, transmutando-lhe, solicita renunciar à ideia de descrever um mundo dado, coletar dados desse mundo para afirmação ou negação de uma hipótese teleológica viii. Nossas pesquisas ensaiam um fazer provisório, "um frágil ponto do qual pode se empreender uma fuga" (FONSECA, 2007, p. 141), um fazer insurgido do espanto diante da pequenez desse mundo em que nos constituímos, desse (nosso) tempo, mas também do encanto com as forças germinativas, os germes de mundos outros que circulam num avessar o aqui-e-agora. Pesquisamos, pois, com "gestos e paisagens corporais [...] 'dispersas', onde explodem singularidades” (VASCONCELOS; BALESTRIN; PAULON, 2013, p. 605).

Na tentativa de expor essas apostas no inimaginável da pesquisa e da vida, esse texto se constrói aos poucos no apontamento de certa historicidade que move as políticas de educação infantil realizadas nos currículos escolares e em suas formas de apreender a infância. Mas ele germina também das possibilidades do método da etnocartografia de tela, um métodoinstalação desenvolvido por uma antropologia visual, rompente ao uso do cinema como ferramenta de registro etnográfico, em antropofagia com o regime atencional da cartografia. Por meio desse movimento metodológico antropofágico, instala-se a possibilidade de produzir com o cinema e com Jonas brechas nesses espaços de conhecimento (KOHAN, 2007), fissuras na escolarização como projeto de civilização branca, heteronormativa, patriarcal, capitalista (VEIGA, 2002). Assim, nossa atenção pousa em como Jonas opera a seu modo uma desobediência e em como as pessoas do seu mundo se colocam nessas (des)obediências. Jonas, encenando uma vida-manifesto: "contra o gabinetismo, a prática culta da vida. [...] contra todos os importadores de consciência enlatada, a existência palpável da vida” (ANDRADE, 1990). 


\section{“Invenção da infância ou infância da invenção?"ix}

Com a obra de Manuel de Barros, Memórias inventadas, Kohan (2007) reflete sobre a condição de possibilidade de verdade que a invenção promove, com a atenção foucaultiana de enxergar a duplicidade da verdade e do verdadeiro. Em meio a essa atenção, permanece a pergunta de quais verdades a infância inventada enuncia, o que diz essa infância forjada socialmente pela norma médico-pedagógica-familiar que marca o corpo infantil? Nesse mesmo movimento, Kohan (2007) aponta a existência infantil que habita em duas temporalidades: uma cronologicamente marcada, o tempo chrónos, sucessivo e datado; e o tempo aión, de intensidade da vida.

Essas infâncias que habitam duas dimensões se diferenciam, co-habitando corpos e mundos humanos. Enquanto a infância como uma etapa do desenvolvimento está sempre a se tornar algo que não ela mesma, a ser superada devido a sua condição menor ${ }^{\mathrm{x}}$, assume status de verdadeiro, de história única; o devir-criança marca a autenticidade do "grão de sem-sentido" (DIDI-HUBERMANN, 2012) que não cabe na finitude do adulto prisioneiro de seus limites (CORAZZA, 2002). Pensar uma infância aiónica intensiva é buscar enxergar o fazer (e não o feito) que foge à tentativa de objetificação da infância, ou além, que brinca com esses dispositivos $^{\mathrm{xi}}$ de saber-poder com um gesto, uma palavra de contravenção. Insistir na potência de uma infância capaz de inquietar o que sabemos, desestabilizando nossas práticas e os lugares nos quais tentamos encaixá-la (LARROSA, 1998) é expor:

[...] uma rede que se estabelece diante de elementos heterogêneos que envolvem os discursos, o espaço escolar, as ideias, o currículo, os materiais escolares, os procedimentos administrativos etc.; a natureza das relações entre esses elementos está no âmbito das relações de poder e é de caráter estratégico, confirmando-as como produtos e produtoras de saber (VEIGA, 2002, p. 91).

Essa rede heterogênea é composta por forças interessadas no objeto-infância (HECKERT, 2018) e em construir conhecimento que estabeleça uma relação de hierarquia com esse corpo a ser assujeitado ${ }^{x i i}$. Dizendo de outro modo, essa rede produz a cara moderna da infância, a inventa como objeto de conhecimento, ditando o que ela necessita para viver, seus comportamentos, suas durações e seus desejos, sempre se forjando sob discursos diferenciados, pautados na saúde, na prevenção e no cuidado consentido com a infância (OLIVEIRA, 2019). O movimento de educabilidade do corpo infante serve ao imperativo da civilidade desse corpo após nascer, o provimento do maná que o fortalece e, como Heckert (2018) afirma, protege-o dos perigos da vida, conservando uma infância em direção à promessa do adulto que se fará ali. 
Segundo Costa (1979), essa infância é conceituada, emergindo como modo de existência do corpo infante, em meados do séc. XIX, quando condições socioeconômicas, políticas e culturais tornaram a politização do cuidado com a criança uma necessidade, atendendo o problema urgente da mortalidade infantil. A progressiva responsabilização da nova figura da mãe é construída a partir da sua expulsão dos espaços públicos e da privatização dos cuidados com a criança. É a criação do lar, lugar para educar os filhos e prepará-los para o futuro, de acordo com seu sexo e suas funções sociais, como aponta Badinter (1985). Deste modo, também se deu início à compartimentalização da infância (família, escola, pediatria, pedagogia etc.), colocada em diferentes espaços de acordo com sua idade e direcionada sob cuidados específicos de acordo com categorias médicas e socioculturais. Com um enorme investimento biomédico, filosófico e cultural (BADINTER, 1985), a ideia da criança a ser educada cai nos braços do povo e, gradativamente, esse corpo infantil torna-se importante o suficiente para que não o deixem morrer (BADINTER, 1985).

A saúde da criança manifesta também a politização do feminino e da maternidade, aos poucos ampliando os cuidados dos manuais médicos também para o corpo da mãe, que deve ser bem alimentado, limpo e devotado para os prazeres da amamentação (MEYER, 2003; COSTA, 1979; MARTINS, 2004; ROHDEN, 2001). Apesar desse movimento ter emergido no século XIX, ele se intensifica ao ponto de o amor materno ser naturalizado e traçado enquanto característica biológica inerente à espécie humana, mesmo que documentos (a história habitual/tradicional) estabeleçam o cenário filosófico, social, cultural e econômico que promove e naturaliza tais clivagens nas maneiras de pensar, perceber, sentir, viver a e com a infância, inventada (BADINTER, 1985).

A educação novecentista, cujos currículos eram fortemente sexistas em torno do que era útil uma menina/um menino aprender em sua juventude, mantém consonâncias com os raciocínios curriculares atuais, os quais produzem um certo ensinar e aprender sobre gênero. Paraíso (2011, p. 147) define o currículo como "um território de ensino" que "governa condutas, produz práticas, inclui e exclui, hierarquiza, normaliza e divide os sujeitos entre quem sabe e quem não sabe, quem é bom e quem é mau aluno, quem tem bom e quem tem baixo desempenho, quem segue e quem não segue as regras etc.”.

Assim, podemos afirmar que se trata de uma maquinação, da ativação de um campo de produção de subjetividades infantis, campo do qual os currículos escolares fazem parte. Por outro lado, a produção heterogênea, a política da multiplicidade que compõe tal campo indica que ele se constitui por meio de diferentes olhares e práticas sobre os corpos infantis, indicando um campo perpassado por disputa de práticas, inclusive de modos de olhar e narrar, o que Revista Interinstitucional Artes de Educar. Rio de Janeiro, V.8, N.1 - pág. 111-133 jan-maio de 2022: "Por uma pedagogia macunaímica" - DOI: 10.12957/riae.2022.65310 
implica a produção de corpos e mundos, de infâncias diferentes. Dessa forma, na tentativa de desnaturalizar discursos e dispositivos inseridos na "biopolítica escolar" (CORAZZA, 1996) que cria veredictos para os territórios existenciais infantis, o cinema, ou ao menos a produção de imagens errantes empreendidas por alguns modos de fazer cinema, pode ser um espaço do (im)possível para a infância e para o projeto civilizatório humano.

\section{Fazer da tela campo atencional: um desafio de (cri)ação}

Articular um modo-outro de ver e pensar as relações e presenças permeadas na infância pode ser fecundado com algumas imagens cinematográficas, tela não de representação, mas de fabulação de um tempo-espaço de narração, de memória que vai se criando nas imagens em movimento. É enxergar a imagem-imaginação, um traço do visível tocado por ela (DIDIHUBERMAN, 2012) e se deixar afetar por ela sem qualquer predominância de passividade ou de concentração, mas gestar uma atenção cartográfica (KASTRUP, 2007): aberta, à espreita, que não busca selecionar nem apreender um suposto objeto de pesquisa.

Como Kastrup (2007) aponta, o desafio da atenção cartográfica está em (des)aprender os mecanismos de inibição presentes na atenção seletiva que por anos fomos construindo, a qual se inclina na direção das expectativas do eu e das percepções compostas pela experiência do sujeito. Expectativas e percepções que estão em consonância com o tecido cultural de um tempo e que funciona para nos situar nele e comunicar, sobreviver (ROLNIK, 2016). Na imensidão da cultura pós-moderna, se desenvolve uma atenção ainda mais hiper-focada ${ }^{\text {xiii }}$, pois há um fluxo sempre crescente e constante de informações a serem lidas, vistas, anunciadas, ouvidas e selecionadas através de uma interioridade emissora de opiniões, é o sujeito da informação e da antiexperiência (LARROSA, 2002). A aceleração que constitui esse fluxo de informações faz faltar o tempo e impede a construção da memória, o encontro e a densidade que proporcionam a experiência.

Por isso, estamos aqui apostando na desnaturalização de um modo de funcionamento da atenção entendido como a-histórico e universal, para dizer que mesmo a atenção entendida como processo humano básico é produzida num tempo e espaço específicos. Assim, seu modo de funcionamento pode ser torcido, podemos como já apontamos, cultivar/adubar outros funcionamentos atencionais, também como modo de nos dissociarmos do tempo presente, intensificando-o e intensificando-nos, semeando uma atenção à movência da vida, uma atençãoarte-pensamento na imanência do vivo e do viver, uma prática de si e de mundos "sempre em vias de si fazer" (FONSECA, 2007, p. 144), no encontro. 
Como indica Calou (2021), trata-se de estar perto e dentro, tornar-se familiar ao campomundo; e ao mesmo tempo ensaiar uma experiência do fora, de estranhar o mundo, situar-se contra, dissociar-se do presente em que habitamos e que nos habita. Podemos dizer, então, que o encontro da etnografia de tela com a atenção cartográfica faz apostar em um entremeio de um pensamento-memória, uma análise que se tece junto à história (um cinema em aliança a imagens clichês de um mundo dado, como ferramenta para a compreensão de determinados contextos históricos e seus modos de ver, perceber, sentir, conviver); e, ao mesmo tempo, um pensamentocriação contra a história (o cinema como produção de imagens que dão expressão a mundos que estão pedindo passagem nas brechas desse mundo dado). Se tais formas de analisar não podem coincidir, elas dão as mãos para articular esses modos-outros de pensar, de olhar; de ver as imagens em movimento.

A etnografia de tela busca: tornar o filme campo de pesquisa (HIKIJI, 1998); envolverse com as narrativas fílmicas a partir de longos períodos de contato com o filme, observação sistemática inclusive das ferramentas cinematográficas utilizadas na composição das imagens; desenvolver diários do campo-tela (BALESTRIN, 2013; PRATES; COSTA; MELO; 2019). Mesmo ainda em um território antropológico, os procedimentos não tomam o filme enquanto objeto de pesquisa distanciado de um sujeito pesquisador, mas um campo vivo de afetação propício para germinar a atenção cartográfica.

Dessa duplicidade geradora da etnocartografia de tela, expõem-se materiais desconexos e desordenados (KASTRUP, 2007) que fazem um cinema emergir como um "desconcerto das imagens", "encarniçando a narração" (PRATES; COSTA; MELO, 2019, p. 139) que desloca sentidos e os multiplica em sua criação de realidades, a imagem-imaginação que arde quando toca o real (DIDI-HUBERMAN, 2012). Mas como (des)aprender o olhar para encontrar Jonas e tudo o que ele faz do possível? Como enxergar os enunciados e as visibilidades (DELEUZE, 2017) que pululam com essas imagens em movimento sem se perceber longe ou distante, de algum modo? Essa é a tentativa que se constrói aqui: o que foi sentido do contato com as imagens e o que pode ser rascunhado a partir disso.

\section{A educabilidade da infância}

Também dos corações onde abotoam

Os sonhos, um a um, céleres voam,

Como voam as pombas dos pombais

Raimundo Correa 
Em close-up ${ }^{x i v}$, um punhado de formigas caminha nos tecidos, fazendo deles território de partilha e construção conjunta. Há Jonas, seu irmão e amigos, garotos da mesma idade, amarrando cordas e moldando pedaços de madeira que formam uma bilheteria. Eles também gestam um espaço de construção conjunta, um território de imaginação: o circo Tropical que viajou a Europa, o Brasil e o mundo, mas se faz ali, no quintal de Dona Neide. Aos poucos, as imagens oferecem pequenos detalhes do organismo que esses amigos compõem: aprendizes das acrobacias e espetáculos, arteiros da memória que se fia nos galhos da mangueira na qual se penduram. Jonas pinta em seu rosto um palhaço. Na penumbra que começa a se formar com o entardecer, ele conversa com Paula.

PAULA: E esse circo, é só pra brincar nas férias ou é pra vida toda?

JONAS: Eu acho que é pra vida toda, eu acho.

PAULA: Mas você gosta mais de fazer o circo ou de estudar?

JONAS: Estudar.

PAULA: É isso, Jonas? (eles riem, Jonas tenta desconversar)

JONAS: É isso, não, o quê? Pera aí. (ele ri também)

PAULA: Fale como é de verdade.

Esse fingimento, movimento de resistência disfarçado de risadas e silêncios (BOUCHERON, 2018), é uma das artes de Jonas, que grita uma vida. A vida de um garoto de 13 anos que deve frequentar a escola - deve ou tem o direito? Tem o direito ou deve? ${ }^{\mathrm{xv}}-$, segundo o que garante e exige a legislação brasileira, movida pela discursividade de uma educação para a prevenção da criminalidade (deslocamento futuro), um investimento que se inicia com a educação na primeira infância (CORREA, 2019). Esse funcionamento atinge especialmente Jonas, cuja existência é atravessada por uma suposta vulnerabilidade social (rastreada a partir de uma classe social a qual ele pode pertencer, o lugar em que mora, a composição familiar etc.) que põe em risco a promessa de civilização moderna, cuja infância representa. Por esse viés, é possível pensar a escolarização como um dispositivo que põe em funcionamento estratégias em relações de poder-saber articuladas a uma rede de discursos (VEIGA, 2002), os quais são orientados por práticas embasadas em saberes cientificamente qualificados e alinhados à razão de Estado (OLIVEIRA, 2016). Todo um conjunto de visibilidades que são ratificadas na fala da professora de Jonas em sala de aula:

[Sala de aula, centralidade do plano no rosto de Jonas, voz em off da professora, Jonas com a caneta na boca ri.] 
PROFESSORA: $O$ problema de um aluno é um problema do professor, é um problema da direção, é um problema social. Porque eu digo sempre, ou você fabrica cidadão, ou você fabrica ladrão. É uon, uon, é assim que funciona.

Esse enunciado da professora performa e reitera o conjunto de estratégias do dispositivo de escolarização supracitado, materializado por um conjunto de pessoas e entidades que fazem parte da fabricação do sujeito social criança, sempre preso em dicotomias: bom ou mau aluno, comportado ou rebelde, obediente ou desobediente (PARAÍSO, 2011; 2016). O sujeito criança aciona a posição de sujeito aluno e, assim, um destino é quase sempre traçado em linha reta a partir dos comportamentos que essa criança assume na escola - um dossiê generalizador de quem ela é. Como a professora diz, "é uon, uon", ou/ou, dicotomia que não suporta ser aberta para brechas de existências que não se encaixam nesse (suposto) determinismo.

Jonas, parte e alvo dessa lógica capitalista de sucesso (quando vir) a ser adulto (homem, branco, trabalhador, ascendendo sua classe social, compondo uma família menos desestruturada que a sua, menos vinculada à 'palhaçada' do circo), pensa com os amigos como pode ganhar dinheiro com o circo desde o quintal de casa até ficar "famoso", como conseguir que seu sonho alcance os mesmos fins sem que precise passar pelo mesmo caminho. A fim de produzir esse corpo amansado (OLIVEIRA, 2016) e obediente, lugar de maquinação do sonho profissional, pratica-se um olhar pedagógico de classificação, observação e descrição dessa infância, seus pontos positivos a serem mantidos e negativos a serem trabalhados para melhoria, como observado por Corazza (1996).

A possibilidade de melhoria do aluno assenta-se no fato do currículo escolar ser um território de aprender e ensinar, mas sobretudo um ensinar baseado na fidelidade à informação (coisas sem movimento), fechando o espaço no qual a diferença poderia se fazer presente e, quem sabe, se fazer visível. É por isso que um filme com Jonas gera tanta surpresa e indignação de alguns colegas e de sua professora, o modo com o qual ele reage e age com relação à escola e aos estudos, o fingimento que ele realiza para as câmeras e sua mãe. Ele vai à escola, mas não presta atenção nas aulas, não estuda em sala e, como uma colega diz, em tom de piada: "Você não faz nada, não faz dever, fica na rampa paquerando armenina, abusando; belo documentário". Endossando-a, a figura de autoridade pedagógica apresenta-se posteriormente, questionando esse "protagonismo" de Jonas, que não age de acordo com as normas escolares para justificar essa atenção recebida:

PROFESSORA: Aluno que não gosta de escola, aluno que vem pra escolar filar aula não é referência pra ninguém, e nem vai ser. Você acha que vai? E por que tem que ser ele? Não pode ser outro aluno? De onde você conhece ele? 
PAULA: Mas por que quando, quando eu estou aqui vejo uma postura dele, quando a gente sai é diferente?

PROFESSORA: Completamente. Vocês saem em seguida ele sai da sala, ele finge que estuda na frente de vocês. Quando vocês se retiram, ele não tem nenhum compromisso. E isso me incomoda, isso pra mim não é referencial pra ninguém. Eu vejo a escola como lugar de aprendizagem, não de brincadeira, de desleixo, e ele é um menino exatamente assim. E ele sabe disso, já conversei diversas vezes, então eu não concordo com esse documentário que vocês tão fazendo.

A escola é entendida como lugar de aprendizagem, mas uma aprendizagem fria e imóvel, realizada em uma única direção: o corpo primitivo infante deve (tem o direito) de tornar-se adulto civilizado por meio de todo um longo percurso de aprendizagens de uma moral de faixa etária, uma moral de gênero, uma moral sanitária e higienista etc. Ela parte do professor a ser ouvido (aqui em masculino de propósito) em silêncio e concordância até o estudante quieto em sua cadeira (e que se enfatize o quieto, sentado e calado) para, assim, absorver ao máximo as informações transmitidas e poder se tornar um adulto cheio de opiniões (com o corpo fechado para a experiência e para o encontro).

Em outros termos, aprendizagem é pensada como uma relação de transmissão-captação, uma objetividade e pureza na sensopercepção que convertesse cada pedaço de coisa "apre(e)ndida" em memória. Aprendizagem: um processamento de informações absorvidas e testadas em formatos específicos de avaliações, as quais demarcam o desempenho em “competências mínimas" que esse aluno deve apresentar. As competências mínimas, como o desempenho na leitura e escrita e em outras matérias da grade curricular, são marcos avaliativos pertencentes à tecnologia do desempenho (PARAÍSO, 2016) que buscam hierarquizar seus estudantes com base numa homogeneidade de seus parâmetros avaliativos e do quê e como os alunos devem aprender.

O conteúdo que precisa ser memorizado e aprendido também é questionado por Jonas, com um jeito 'divertido' de subverter a própria lógica que acredita nesse formato de escolarização necessário para garantir estabilidade financeira. Ele argumenta à mãe, entre risos: "Vai adiantar o que eu saber do faraó que já morreu há milhões de anos? O faraó vai vir de lá do túmulo dele pra vir me dar dinheiro?", enquanto sua mãe insiste na concessão: tem que estudar, senão nada de circo, nem do quintal nem do tio.

A distração ${ }^{\mathrm{xvi}}$ e a criação envolvidas na aprendizagem, o "abrir-se e refazer os corpos, encontrar a diferença" (PARAÍSO, 2011, p. 147) é reservado para momento e lugar adequado, considerando também a idade adequada. Nesse cenário de aprendizagem escolarizada, ainda que haja presença e valorização da brincadeira, ela está colocada de forma especificamente indicada: a função do lúdico na aprendizagem infantil. Assim, as forças brincantes da vida ficam 
subsumidas a uma tarefa a ser cumprida: fazer a criança se desenvolver e se tornar adulta, ignorando seu aspecto inventivo e germinador da diferença (BAPTISTA, 2018). É uma afirmação de um modo particular de infância que também nega suas processualidades — a não ser restringindo processo a processamento de dados — que faz a pomba somente caminhar, enquanto ela possui asas, bico e olhos. É negar o "saber-do-corpo" (ROLNIK, 2016) que Jonas expressa com o circo, a aprendizagem de corpo inteiro que ele realiza agenciando-se com aquilo que lhe move e encontrando-se com a errância da vida (VASCONCELOS; MELO; OLIVEIRA, 2017).

\section{Na escola, torno-me homem}

No artigo "Gente é mais que homem", derivado de uma pesquisa de doutorado num Centro de Atenção Psicossocial para Álcool e outras Drogas (CAPS ad), Vasconcelos, Seffner e Melo (2020) destacam o seguinte fragmento de fala de um usuário do serviço: "No CAPS, voltei a ser homem". Que sentidos estariam operando nessa frase? Os autores argumentam que o CAPS ad funciona como lócus educativo que investe na produção de determinados sujeitos e corpos. Seu projeto institucional, terapêutico e corporal tem como objetivo produzir cidadãos/ãs de bem, cuidadores/as de si, responsáveis, autônomos/as e participantes do projeto civilizatório (neo)liberal. Eles assinalam:

Todos/as e cada um/a de nós, corpos organizados, corpos marcados pelo poder, corpos governados e governáveis, cidadãos/ãs responsáveis, devemos ao Estado e ao mercado. Primeiramente, devemos ser individualizados, identificados, organizados, únicos, sujeitados, saudáveis. Devemos ser grupos e comunidades delimitados, cujo reconhecimento também advém via luta por identidade. Identidades, mesmo as dissidentes, devem ser reconhecidas - e, desse modo, também advir soberanas também os corpos 'resistentes' devem construir um 'rosto' homogêneo. Direitos e deveres: identidade, delimitação, depuração, controle. Devemos ser corpos individuais e sociais que marcham com o Estado e o mercado. "No CAPS, voltei a ser homem". O Homem, o homem da razão, possuidor de uma identidade indivisa e soberana, masculino, branco, adulto, heterossexual, trabalhador, viril, 'encorpado', sadio, 'chefe' de família que tem um nome a zelar e dá esse nome à família, que tem bens e patrimônios a honrar e que honram esse nome, que controla e domina sua 'fêmea', que só ele a trai ou pode traí-la, que tem autocontrole sobre o uso que faz de drogas, que faz uso 'responsável' de álcool e outras drogas, que tem poder de consumo, de endividamento, cartão de crédito, que tem casa, endereço fixo, que é cidadão, tudo isso lhe concedendo um local de poder e de autoridade como sujeito universal: a humanidade (VASCONCELOS; SEFFNER; MELO, 2020, p. 9).

Nessa mesma direção, o objeto-infância ${ }^{x v i i}$ é constituído e tomado: educar para a cidadania. Dessa maneira, há outros componentes que integram o currículo infantil, tais como as normas de gênero. A escola, como dispositivo de escolarização, está em conformidade com saberes normativos (OLIVEIRA, 2016) que estabelecem relações de poder-saber reguladoras 
de gênero. Gênero, definido aqui como uma norma regulatória de condutas, engrenagem de produção e naturalização do masculino e feminino, incluindo "formas intersticiais, hormonais, cromossômicas, físicas e performativas que o gênero assume" (BUTLER, 2014, p. 253) é maquinado nesses espaços sociais e educacionais segundo também as atribuições que os adultos realizam. O currículo, embebido de gênero e saberes biomédicos, diferencia as capacidades e condutas de meninos e meninas pelo que se é esperado e entendido adequado, classificando e normalizando formas de aprendizagem. Assim, por exemplo, percebe-se como menos problemático um aluno agitado e indisciplinado e se espera que uma aluna performe maior capacidade de concentração, obediência e controle da agressividade (PARAÍSO, 2011; 2016).

Paraíso (2011) reflete ainda sobre o conflito que existe no menino em escolarização: ser aquele engraçado e desobediente que os seus amigos gostam e endossam, ou o garoto obediente e estudioso valorizado pelos professores e escola? Nesse sentido, 'más' condutas são esperadas desses meninos e até mesmo maquinadas pelo ambiente escolar e seus modos de ensinar, como demonstra a professora de Jonas, ao afirmar que ele mesmo sabe que é descompromissado e desleixado. É a reafirmação constante da inadequação do garoto ao espaço escolar, é uma negação da diferença que pode existir entre crianças e seus modos de aprender, classificadas segundo critérios que buscam hegemonias, hierarquizações e dicotomias.

Aí está, porém, a engrenagem dupla expressada pela desobediência de Jonas: ao mesmo tempo em que ele foge da norma civilizadora do assujeitamento-cidadão, afirma uma posição de condutas fortemente generificadas, mas que também se conectam ao merecimento de atenção e ajuda de um garoto às margens, ele precisa se esforçar, ser trabalhador (COIMBRA; LOBO; NASCIMENTO, 2009) para ingressar nessa construção do adulto responsável. Há, então, uma inadequação de Jonas principalmente pela negação que suas desobediências representam, negação da oportunidade que é frequentar uma escola, sendo ele um menino que não é branco, não é rico e mora na região periférica de Salvador. Mas que sentidos operam essa inadequação, não para Jonas, mas para esse conjunto de saberes e práticas classificatórias?

\section{A culpa (não) é de fidel, é da mãe $e^{x v i i i}$}

Em medida semelhante, mas por outros olhares, a inadequação de Jonas, como a de outros meninos e meninas em sua idade, é um peso de responsabilidade majoritariamente 'feminino', sendo tomado pela mãe ou pela avó, mesmo que haja "presença" de um pai no cuidado da criança. Em 1775, Buchan afirmou a essencialidade da mulher-mãe na produção de 
cidadãos, já que "graças a elas, os homens passam bem ou adoecem; graças a elas, os homens são úteis no mundo ou se transformam em pestes na sociedade" (BADINTER, 1985, p. 182). Nos currículos escolares analisados por Paraíso (2011), são as mulheres (professoras e mães) que compõem a escola e são colocadas como as mais importantes no apoio e acompanhamento das crianças. Assim como são tidas como essenciais na formação do cidadão democrático trabalhador, são também mais responsabilizadas pelos problemas de desobediência ou mau desempenho dos alunos.

Essa posição da mãe é atrelada ao movimento de politização da maternidade como papel social por essência feminino, uma obrigação perante à saúde e à educação dos filhos, à solidez de sua família e da pátria (MEYER, 2003; 2005). Assim, articula-se um suposto instinto biológico natural afetuoso ao sucesso no desenvolvimento de seus filhos. Exige-se cada vez mais investimento dessa mulher-mãe sobre si mesma e sobre a criança, em uma lógica biopolítica-disciplinar de cuidado médico e autorregulação do corpo da mulher desde uma certa idade, para mantê-lo saudável o suficiente para o feto, ou mantê-lo saudável para prolongar a escolha de ter ou não filhos. Atentar para o fato de que a escolha por ter filhos deve ser sempre com responsabilidade, sabendo das necessidades que um filho traz, e as consequências negativas da má criação. Ou seja, tendo-se ou não filhos, a sinonímia mulher-mãe prossegue operando corpos de mulheres (MEYER, 2003; 2005).

Ao longo de todo o documentário, a já mencionada dualidade de fabricar cidadão ou ladrão é lembrada como destino possível para garotos como Jonas. São notícias de rádio e TV que falam do aumento na criminalidade da região metropolitana de Salvador, a maior incidência de jovens entre 15 a 25 anos como "aliciados pelo crime" e a controversa discussão da Proposta de Emenda à Constituição (PEC) que pretendia reduzir a maioridade penal dos 18 para os 16 anos. É, também, desse lugar entre cidadão e ladrão do qual a mãe de Jonas pede para que os meninos evitem passar a divulgar o circo do quintal. É como se o perigo da maternidade mal conduzida estivesse sempre à espreita, observando quais decisões podem carregar essas vidas para essa realidade. Dicotomia e escolha (individual, individualizada).

Essa dicotomia faz questionar qual infância está no cerne de uma luta em prol da conservação de (nossos) valores civilizatórios (HECKERT, 2018), considerando a proposição de uma diminuição na maioridade penal e, portanto, da infância menorizada que precisa de cuidado, proteção, direcionamento e, por vezes, confinamento: se a mãe não conseguiu cuidar, o Estado-polícia proverá. É mais uma preocupação para a mãe, que seu filho não se torne um "menor" (nomenclatura/estigma atribuída a garotos marginalizados, usualmente negros, 
advindos de bairros periféricos, de famílias tidas como 'desestruturadas', e entendidos como tendentes a se envolver com a criminalidade).

A preocupação da mãe de que Jonas se junte ao circo está ligada a ele não continuar seus estudos formais e não ter quem cuide dele, como Wilma expõe em alguns momentos de desabafo com Paula: "Imagine Jonas no circo, ele não vai se dedicar nos estudos. Sem falar outra preocupação que eu tenho, pra lá e pra cá, acidente nas estradas". Já na visita ao circo, ela continua a demonstrar esse receio, agora também para seu irmão, que apoia e afirma o talento de Jonas para a vida circense "Jonas vindo pra cá, vai dormir aonde? Vai comer aonde? Quem é que vai cuidar dele?".

A responsabilidade pelo erro e pelo acerto confere também "privilégio" na autoridade da mãe sobre as crianças, é ela que sabe o melhor para os fillhos e que tem a última palavra em muitas decisões. Aí talvez estejam alguns indícios da obediência que permanece em Jonas, sem esquecer de seu berço nordestino, tradicionalmente grande valorizador de hábitos culturais e religiosos, do respeito aos mais velhos e da "benção" ao acordar e ao dormir. Sua vida circense indica uma organização que centraliza a família e o cuidado compartilhado de uns com outros, pregando o respeito à mãe e aos mais velhos, traduzido em obediência aos seus modos de governar as condutas infantis.

Com interesse em olhar para as (des)obediências, Grós (2018) insiste em uma pergunta às avessas, não a da existência e motivação para desobedecer, mas a da continuidade da obediência: por que obedecemos? Ele explora diferentes modos de obedecer e desobedecer não como dicotomias de escolha única, mas como planos que podem se cruzar, atravessar e misturar, e acima de tudo co-geracionar os movimentos dos sujeitos, abrindo um campo de dinamismo, atentando-se ao que é possível nessas relações de autoridade. Apesar de haver uma certa "fragilidade servil da infância" (BAPTISTA, 2018, p. 167), Jonas exerce um tipo de “submissão deferente" (GRÓS, 2018, p. 44), pois explora toda uma "teatralização de sinais de obediência" (GRÓS, 2018, p. 23): é o acordar de manhã cedo, tomar café fardado, estar em sala de aula, mas é também a ausência (em atenção e vontade) da sala de aula, dos estudos, das ordens da professora marcando uma desobediência mais 'concreta'.

Baseado na ideia de uma infância tutelada, forjada historicamente (BADINTER, 1985; COSTA, 1979), obedecer é cumprir com o papel de criança-doce para harmonizar o ambiente familiar, evitar desarranjos e preocupações exacerbadas. Porém, "as forças do mundo não cabem todas numa só pessoa; o mundo está cheio delas, diferentes, contrastantes, de várias intensidades" (BAPTISTA, 1999, p. 77). Jonas transborda, seu corpo é marcado por pluralidades, intensidades diferentes, pelas batalhas e capturas não-aleatórias pelos saberes que 
engendram sua realidade infante. Jonas vaza sua inconformidade (não cabe na forma-criança), transparece suas questões e força o movimento desses saberes ao sempre dobrar essas linhas para o fora. Mas, o que pode o cinema com Jonas? O que pode Jonas com o cinema?

\section{Do corpo que vaza às telas que vazam: possibilidades de afetação}

(Des)aprender olhares para pensar com filmes por meio do exercício de etnocartografar envolve encontros de quem está cá e quem está lá, virtualmente. É, também, pensar como podem se dar esses encontros em meio a tantas telas: a tela da câmera responsável por registrar as imagens, os sons, a poeira da batalha; a tela que nos transporta essa vivência; a tela das chamadas de vídeo. Essa experiência fílmica é feita pelos encontros, pelas amizades, a ligação de Jonas que convida o antropólogo ao cinema, o cineasta ao circo, a escola à vida, encontros que vazam das paredes escolares, encontros que vazam a tela, encontros devir,perscrutando uma vida. Encontro entre imagens, cores, sons, personagens, cenas, nós. Encontro existencial, "momento prático - e não representativo - da sensação. Superação do organismo, corpo intensivo [...]. A sensação como vibração" (FONSECA, 2007, p. 149).

Do conjunto das combinações, o documentário criativo, conduzido quase sempre nos ângulos e cortes mais comuns, mistura a intencionalidade da equipe em uma narrativa que se realiza enquanto é feita, não somente observada. Há uma evocação dessas pessoas para se fazerem visíveis, fazerem filme "sob o risco do real" (MESQUITA, 2011, p. 54). E aí se coloca a palavra evocar para fazer pensar na memória fecundada no filme, um tempo de intensidade tal como a infância tomada como experiência (KOHAN, 2007). No que é posto, fica vivo tatear variados sentidos do diálogo entre Paula e Jonas sobre os motivos de fazer um filme com ele.

PAULA: E aí, como foi hoje? (na escola)

JONAS: Hoje foi bom, foi normal, normal não que foi um bocado de gente que eu não conhecia veio falar comigo. Perguntando por que que tá fazendo filme, porque não fazia filme de outras pessoas, que se eu era mais importante do que outras pessoas. Aíficava mesmo sem saber o que dizer, aí fiquei mesmo por que vocês tão fazendo filme sobre mim(?)

PAULA: Hum, porque cê tem seu circo né e a gente tem nossos filmes. E pra você fazer seu circo dá um trabalhão danado, tem que lutar um bocado e pra gente fazer os filmes também. E pra fazer o circo você precisa juntar seus amigos, a gente pra fazer os filmes também tem que juntar nossos amigos. Mas aí se a gente não conseguir fazer os filmes...

JONAS: É uma facada no meu coração. 
PAULA: Se você não fizer seu circo também é uma facada no meu coração. Por isso a gente faz um filme juntos.

O filme feito no quintal de casa e que viaja o mundo é um duplo do circo que viaja o mundo e pára no quintal de Dona Neide. Os encontros constroem um tempo singular, tempo de fazer memória, a qual se produz nesse espaço do devir, o espaço da brecha, o entre que se passa nesses encontros de ideias, histórias (ocorrências do corpo), que proporciona o pensar (KOHAN, 2011). É um filme cujo roteiro é posfácio, sem teleologias. Jonas e o circo sem lona faz emergir a relação do pensamento com a arte, da qual o circo compartilha também: a criação, a amizade, uma certa relação de equidade, o abraço de uma diferença na qual o outro é outroeu em heterogeneidade. A amizade entre Wilma (mãe de Jonas) e Paula que desponta as sinceridades, medos e desabafos da responsabilidade de ser mãe e construir um sujeito-cidadão; a amizade entre os garotos do circo do quintal, que imaginam por um tempo o sonho de Jonas; a amizade de Jonas com sua avó, que ri junto com ele das proibições, dos saltos que dão errado e daqueles que dão certo. A amizade "é uma máquina de guerra contra as comunidades de obediência. Ela se alimenta de discussões, concessões, compartilhamentos" (GRÓS, 2018, p. 32). Fazer cinema, fazer circo é tecer amizades, políticas de afetação pelo que se passa, pelo que pede passagem. É editar a própria história e histórias outras para produzir esse espaço em que a memória se realiza em imaginação, é produzir imagens que tocam o real (CARVALHO; COSTA, 2011; DIDI-HUBBERMAN, 2012).

Nesse sentido, o agenciamento de Jonas com o fazer fílmico, o contato com a arte cinematográfica, permitiu a abertura de outro caminho. Descaminho que não se inscreve na dicotomia da civilidade que prega o cidadão x ladrão. Pensar nas existências que fogem desses dispositivos de infantilidade, ou até mesmo, que se realizam na brecha desses dispositivos, no par avesso do poder: a resistência. O contato com o cinema permitiu outro saber-do-corpo (ROLNIK, 2016) em Jonas, aprendizagem do movimento que não se finda, como responde Paula, sobre as continuidades e potencialidades de Jonas: "Esse não é o final do seu filme, é o fim desse filme". A memória permanece em fazer, o cinema permanece no fazer, a infância continua, "porque a infância (sempre) tem a ver com nascimentos” (VASCONCELOS; MELO; OLIVEIRA, 2017, p. 69).

\section{Considerações sobre uma existência que não se esgota}

Nesse texto, esboçamos um olhar que ainda se (des)caminha junto a Jonas. A tentativa feita foi de apontar singularidades que podem quando ousamos desemaranhar o dispositivo Revista Interinstitucional Artes de Educar. Rio de Janeiro, V.8, N.1 - pág. 111-133 jan-maio de 2022: "Por uma pedagogia macunaímica" - DOI: 10.12957/riae.2022.65310 
infantilidade por meio do agenciamento das telas com a realidade, do que se pode enxergar das visibilidades apresentadas com as imagens em movimento. Ao enredar cinema e circo, há uma afirmação do devir da infância, mesmo ela atravessada por um imperativo de fazê-la objetoinfância. Ao acompanhar e criar uma memória imaginativa fabuladora de mundos, o filme faz emergir a diacronia, os paradoxos que habitam a infância, faz tremer o instituído, dando vazão aos saberes desses seres pequenos que pululam em nós, tecendo uma revolta menos heroica, menos vistosa, entre a obediência e rebelião, fabulando outros modos de viver.

Falar com Jonas é falar do que é possível fazer, da mangueira no quintal da casa da avó, da mãe pendurando roupa no varal, da diretora de filme sentada no chão vinho chamuscado lutando com os polegares, da professora passando prova avaliativa e das risadas com os amigos. É falar com muita coisa. Deixar que as imagens saltem e corram pelo quintal de terra da avó enquanto Jonas tem 13 anos e seu corpo infantil pode o mundo. Jonas infante, afeito a novos nascimentos, a novos começos de vida, novos inícios de mundo, aparições brincantes e brincando com a sina dos corpos infantis de se tornarem adultos sérios, engajados numa moral civilizatória.

Nesse sentido, o cinema como campo continua a ser potente, não se finda num filme, vaza e faz chão de quintal com a vida. Assim como onde há poder há resistência, onde há essas tentativas reiteradas de forma, de responsabilização e obediência, haja também risadas, piruetas e amizade.

\section{Referências}

ANDRADE, Mário de. Teatro-circo: do Brasil ao Far-West - Piolin. Terra roxa e outras terras, São Paulo, ano 1, n. 3, 27/02/1926. Disponível em <http://memoria.bn.br/docreader/DocReader.aspx?bib=387274\&pagfis=23>. Acesso em 14 nov. 2021.

ANDRADE, Oswald de. Manifesto antropófago [1928]. In: ANDRADE, Oswald de. A utopia antropofágica. São Paulo: Globo, 1990. Obas completas de Oswald de Andrade.

BADINTER, Elisabeth. Um amor conquistado: o mito do amor materno. Tradução de Waltensir Dutra. Rio de Janeiro: Nova Fronteira, 1985.

BALESTRIN, Patrícia. Le Fate Ignoranti: a sexualidade levada a sério. Bagoas - Estudos gays: gêneros e sexualidades, v. 7, n. 10, p. 73-89, 2013. Disponível em:

<https://periodicos.ufrn.br/bagoas/article/view/5376>. Acesso em: 03 maio 2021

BAPTISTA, Luis Antonio. Ética e barbárie de um gesto: a fragilidade servil da infância. In: RODRIGUES, Alexsandro (org.). Crianças em dissidências: narrativas desobedientes. 
Salvador: Devires, 2018, p. 167-183. BAPTISTA, Luis Antonio. A cidade dos sábios. In: BAPTISTA, Luis Antonio. A cidade dos sábios. São Paulo: Summus, 1999, p. 51-96.

BOUCHERON, Patrick. Como se revoltar? São Paulo: Editora 34, 2018.

BUTLER, Judith. Regulações de gênero. Cadernos Pagu, Campinas, n. 42, p. 249-274, jun. 2014. DOI: <http://dx.doi.org/10.1590/0104-8333201400420249>.

CALOU, Antonio Leonardo. "Ano passado eu morri, mas esse ano eu não morro": micropolíticas do desejo de morte e práticas de resistência em trajetos homossexuais. Qualificação de tese de doutorado. UFRN/PPGPSI: Rio Grande do Norte, 2021.

CAMARGO, Robson Corrêa de. A pantomima e o teatro de feira na formação do espetáculo teatral: o texto espetacular e o palimpsesto. Revista de História e Estudos Culturais, Goiânia, vol. 3, n. 4, p.1-32, 2006. Disponível em:

<https://www.revistafenix.pro.br/revistafenix/issue/view/9>. Acesso em: 17 janeiro 2022.

CARVALHO, Emílio; COSTA, Samira. As potências da narrativa. In: LOPES, Kleber; CARVALHO, Emílio; MATOS, Kelma (org.). Ética e as reverberações do fazer. Fortaleza: Edições UFC, 2011, p. 60-73.

CARVALHO, Sérgio. Reflexões sobre o tema da cidadania e a produção de subjetividade no SUS. In: CARVALHO, Sérgio; BARROS, Maria; FERIGATO, Sabrina. (orgs.). Conexões: saúde coletiva e políticas da subjetividade. São Paulo: Aderaldo \& Rothschild, 2009, p. 23-41.

COIMBRA, Cecilia; LOBO, Lilia; NASCIMENTO, Maria. A invenção do humano como modo de assujeitamento. In: MENDONÇA FILHO, Manoel; NOBRE, Maria Teresa (orgs.). Política e Afetividade: narrativas e trajetórias de pesquisa. Salvador: Edufba, 2009. p. 31-42.

CORAZZA, Sandra. Des-ilusão tem futuro?: artistagem da infância. In: COLOQUIO DO LEPSI IP/FE-USP, 4., 2002, São Paulo. Disponível em:

$<$ http://www.proceedings.scielo.br/scielo.php?script=sci_arttext\&pid=MSC00000000320020 00400036\&lng=en\&nrm=abn>. Acesso em: 24 abr. 2021.

CORAZZA, Sandra. Olhos de poder sobre o currículo. Educação e Realidade, Porto Alegre, v. 21, n. 1, p. 46-70, jun. 1996. Disponível em: < https://seer.ufrgs.br/educacaoerealidade/article/view/71640/40636>. Acesso em 03 maio 2021.

CORREA, Bianca. Educação na primeira infância: direito público x capital humano. In: CÁSSIO, Fernando et al (orgs.). Educação contra a barbárie: por escolas democráticas e pela liberdade de ensinar. São Paulo: Boitempo, 2019, p. 83-90.

CORREA, Raimundo. As pombas. Disponível em: <https://www.escritas.org/pt/t/7991/aspombas>. Acesso em: 24 abr. 2021.

COSTA, Jurandir. Ordem médica e norma familiar. Rio de Janeiro: Editora Graal, 1979.

DELEUZE, Gilles. Conversações. São Paulo: Editora 34, 1992. 
DELEUZE, Gilles. Michel Foucault: as formações históricas. Tradução de Cláudio Medeiros e Mario Antunes Marino. São Paulo: N-1 Edições e Editora Filosófica Politeia, 2017.

DIDI-HUBERMAN, Georges. Quando as imagens tocam o real. PÓS: Revista do Programa de Pós-graduação em Artes da EBA/UFMG, p. 206-219, 2012. Disponível em: < https://periodicos.ufmg.br/index.php/revistapos/article/view/15454>. Acesso em: 24 abr. 2021.

FONSECA, Tania. Cartografias da Arteloucura: a insurgência de um outro espaço. In: FONSECA, Tania; ENGELMAN, Selda; PERRONE, Claudia. Rizomas da Reforma Psiquiátrica: a difícil reconciliação. Porto Alegre: Sulina, 2007, p. 141-152.

FOUCAULT, Michel. Nietzsche, a genealogia e a história (in) FOUCAULT, M. Arqueologia das Ciências e história dos sistemas de pensamento: Ditos e escritos II. Rio de Janeiro: Forense Universitária, 2005, p. 260-306.

GALLO, Silvio. O pequeno cidadão: sobre a condução da infância em uma governamentalidade democrática. In: RESENDE, Harold de (org.). Michel Foucault: o governo da infância. Belo Horizonte: Autêntica Editora, 2015. p. 329-342.

GENTILI, Pablo. Educar para o desemprego: a desintegração da promessa integradora. In: FRIGOTTO, Gaudêncio. Educação e crise do trabalho. Petrópolis: Vozes, 2012, p. 76-99.

GROS, Frédéric. Desobedecer. Tradução de Célia Euvaldo. [S. L.]: Ubu Editora, 2018.

HECKERT, Ana Lúcia Coelho. Por uma infância menor. In: LOBO, Lilia; FRANCO, Débora (orgs.). Infâncias em devir: ensaios e pesquisas. Rio de Janeiro: Garamond, 2018, p. 325-339.

HÍKIJI, Rose. Antropólogos vão ao cinema - observações sobre a constituição do filme como campo. Cadernos de Campo (São Paulo - 1991), [S. l.], v. 7, n. 7, p. 91-113, 1998. DOI: <http://doi.org/10.11606/issn.2316-9133.v7i7p91-113>.

JONAS e o circo sem lona. Direção: Paula Gomes. [S.I.] Vitrine Filmes, 2015, 82 min.

JULLIER, Laurent; MARIE, Michel. Lendo as imagens do cinema. São Paulo: Editora SENAC, 2012.

KASTRUP, Virgínia. O funcionamento da atenção no trabalho do cartógrafo. Psicologia \& Sociedade, Porto Alegre, v. 19, n. 1, p. 15-22, abr. 2007. FapUNIFESP (SciELO). DOI: <http://dx.doi.org/10.1590/s0102-71822007000100003>.

KOHAN, Walter Omar. A infância da educação: o conceito devir-criança. In: KOHAN, Walter Omar. Infância, estrangeiridade e ignorância. Belo Horizonte: Autêntica, 2007. p. 8598.

KOHAN, Walter Omar. Infância: entre educação e filosofia. 2. ed. Belo Horizonte: Autêntica Editora, 2011. 
LARROSA, Jorge. Notas sobre a experiência e o saber de experiência. Revista Brasileira de Educação, n. 19, p. 20-28, abr. 2002. FapUNIFESP (SciELO). DOI: <http://dx.doi.org/10.1590/s1413-24782002000100003>.

LARROSA, Jorge. O enigma da infância ou o que vai do impossível ao verdadeiro. In: LARROSA, J.; PÉREZ DE LARA, N. (org.) Imagens do outro. Trad. Celso Márcio Teixeira. Petrópolis/RJ: Vozes, 1998. Disponível em: <http://www.lite.fe.unicamp.br/cursos/ep403/txt3.htm\#: :text=O\%20que\%20vai\%20do\%20p oss\%C3\%Advel,em\%20desacordo\%20com\%20o\%20real>. Acesso em: 29 abr. 2021.

MARTINS, Ana Paula. Visões do feminino: a medicina da mulher nos séculos XIX e XX. Rio de Janeiro: Editora Fiocruz, 2004.

MELO, Marcos; VASCONCELOS, Michele; SOUZA NETO, Edson. "Os dentes afiados da vida preferem a carne na mais tenra infância": etnocartografar com olhos de besta. Childhood \& Philosophy, Rio de Janeiro, v. 16, n. 36, p. 01-28, 18 nov. 2020. Universidade de Estado do Rio de Janeiro. DOI: <http://dx.doi.org/10.12957/childphilo.2020.48116>.

MESQUITA, Cláudia. Um drama documentário? - atualidade e história em "A cidade é uma só?" Revista Devires - Cinema e Humanidades, Belo Horizonte, v. 8, n. 2, p. 48-69, 2011. Disponível em: < https://issuu.com/revistadevires/docs/engajamentos1>. Acesso em: 29 abr. 2021.

MEYER, Dagmar. Educação, saúde e modos de inscrever uma forma de maternidade nos corpos femininos. Movimento (Esefid/Ufrgs), Porto Alegre, v. 9, n. 3, p. 33-58, 26 dez. 2003. Universidade Federal do Rio Grande do Sul. DOI: <http://dx.doi.org/10.22456/19828918.2817>.

MEYER, Dagmar. A politização contemporânea da maternidade: construindo um argumento. Gênero, Niterói, v. 6, n. 1, p. 81-104, 2005. DOI: <https://doi.org/10.22409/rg.v6i1.198>.

OLIVEIRA, Sandra. Psicologia e pastorado laico: pensando as estratégias de governo da infância. Gavagai - Revista Interdisciplinar de Humanidades, v. 5, n. 1, p. 78-96, set. 2019. DOI: <http://dx.doi.org/10.36661/2358-0666.2018n1.11061>.

PARAÍSO, Marlucy Alves. Raciocínios generificados no currículo escolar e possibilidades de aprender. In: LEITE, Carlinda et al (org.). Políticas, Fundamentos e Práticas do Currículo. Porto: Porto Editora, 2011, p. 147-160.

PARAÍSO, Marlucy Alves. Currículo e relações de gênero: entre o que se ensina e o que se pode aprender. Revista Linhas, Florianopólis, v. 17, n. 33, p. 206-237, abr. 2016. DOI: <http://dx.doi.org/10.5965/1984723817332016206>.

PRATES, Rui; COSTA, Pedro; MELO, Marcos. Infância e balbucios: experiências de etnografia de tela numa mostra fílmica. In: NOGUEIRA, Adriana Dantas; FRANÇA, Lilian Cristina Monteiro; SILVA, Renato Izidoro da. Cinema e interdisciplinariedade: convergências, gêneros e discursos. Aracaju: Criação, 2019, p. 137-152.

ROHDEN, Fabíola. Uma ciência da diferença: sexo e gênero na medicina da mulher. Rio de Janeiro: Editora Fiocruz, 2001. 
ROLNIK, Suely. Entrevista com Suely Rolnik: a hora da micropolítica. A hora da micropolítica. 2016. Disponível em: <https://www.goethe.de/ins/br/pt/kul/fok/rul/20790860.html>. Acesso em: 24 abr. 2021.

ROLNIK, Suely. Esferas da insurreição: notas para uma vida não cafetinada. São Paulo: N-1 edições, 2018.

VASCONCELOS, Michele; BALESTRIN, Patrícia Abel; PAULON, Simone Mainieri. Escutar silêncios, povoar solidões: há vida secreta nas palavras. Fractal: Revista de Psicologia, Rio de Janeiro, v. 25, n. 3, p. 603-628, set./dez. 2013. DOI: <https://doi.org/10.1590/S1984-02922013000300012>.

VASCONCELOS, Michele; MELO, Marcos; OLIVEIRA, Roselusia. Imagens, narrativas, culturas infantis em "Abril despedaçado": tateando um modo de olhar. Revista Tempos e Espaços em Educação, São Cristóvão, v. 10, n. 21, p. 67-76, jan./abr. 2017. DOI: <https://doi.org/10.20952/revtee.v10i21.6333>.

VASCONCELOS, Michele; SEFFNER, Fernando; MELO, Marcos. "Gente é mais que homem": gênero e cuidados em álcool e outras drogas. Educar em Revista, Curitiba, v. 36, e75406, p. 1-22, 2020. DOI: <https://doi.org/10.1590/0104-4060.75406>.

VEIGA, Cynthia. A escolarização como projeto de civilização. Revista Brasileira de Educação, Rio de Janeiro, n. 21, p. 90-103, dez. 2002. DOI: <http://dx.doi.org/10.1590/s1413-24782002000300008>.

1 As pantomimas são formas teatrais consolidadas no Império Romano, caracterizando-se como texto espetacular, por sua forma híbrida de gêneros diversos, de teor farsesco, reforçada em seu caráter de ação mimética, que alternava canções e diálogos, silenciosos ou não (CAMARGO, 2006).

ii Jornal literário dirigido por Antonio Carlos Couto de Barros e Antônio Alcântara Machado.

iii Por encontro, compreendemos um espaço de experimentação que se faz entre ideias e/ou corpos, com o desconhecido, o estranho, a diferença (LARROSA, 1998).

iv Segundo Gentili (2012), a promessa integradora da escola fundada na premissa de criar um conjunto de estratégias educacionais para a expansão e ocupação do mercado de trabalho entrou em declínio a partir da década de 1970 e, em certo sentido, expressa a desintegração do imaginário liberal escolar surgido no séc. XIX.

v Não podemos deixar de mencionar que nossa pátria mãe gentil chamada Brasil gestou-se associada a tal projeto civilizatório de face liberal e desenvolvimentista, onde o humano subsome-se à forma-Homem branco, europeu, heterossexual, pai provedor, capitalista homem "de bem e de bens" por meio da educação provida por mulheres. Essa educação é entendida como sendo de papel 'natural' e central das mulheres: maternar/educar para a inclusão das crianças no berço civilizatório da pátria mãe gentil, gentil apenas com os/as poucos/as que alcançam esse berço esplêndido. E se o/a filho/a falhar nessa adesão, a culpa é da ausência ou ineficiência desse tipo específico de maternagem higienista.

vi Enunciável e visível são colocados aqui enquanto conceitos extraídos de Foucault. Enunciado (coisas) faz referência à materialidade escrita e falada envolvida no que é dito e não-dito de uma formação histórica. Visibilidade refere-se, por sua vez, ao plano de proposições visíveis e não visíveis possíveis nesse mesmo extrato histórico. Os dois planos formam redes de composição de saberes, fazeres, procedimentos e formas de proceder, modos de dizer e ver, habitações. Para aprofundamento dos conceitos de enunciado, visibilidade e formação histórica, ver Deleuze (2017).

vii À infância subsumida à primeira etapa do desenvolvimento humano, costuma-se atribuir um estado de minoridade entendido como falta de razão e incapacidade e, assim, como estágio a ser suplantado. A superação da condição menor ocorre em direção à adultez racionalizada e, portanto, emancipada. Heckert (2011) traça críticas a essa colocação e defende uma infância menor com base em Deleuze (2002), ao afirmar a condição menor da infância como um devir, uma abertura para pensar os modos de viver e as regras de conduta instituídas e as romper, produzindo outros modos de existência. Para mais detalhes, consultar a nota x abaixo.

Revista Interinstitucional Artes de Educar. Rio de Janeiro, V.8, N.1 - pág. 111-133 jan-maio de 2022: "Por uma pedagogia macunaímica" - DOI: 10.12957/riae.2022.65310 
viii A pesquisa genealógica de Foucault ([1971], 2005) busca inverter um papel comum da história, o qual a reduz a suas causas finais, como uma teleologia (estudo dos fins). Longe da busca de uma verdade essencial, primeira, Foucault volta a história contra seu nascimento. Buscamos, assim, romper com o papel da pesquisa em coletar dados na busca de resultados finais (os quais costumam ser o foco) e construir uma pesquisa voltada ao processo. A produção de dados (KASTRUP, 2007), característica da etnocartografia de tela, busca "acompanhar devires no encontro com a tela e as conexões desta tela com a diferença que também a ultrapassa" (MELO, VASCONSELOS, SOUZA NETO, 2020, p. 9).

ix A frase foi extraída de Kohan (2007), que brinca com o devir-criança da invenção "versus" um objeto-infância. x Badinter (1985) afirma que a menoridade (ou minoria) toca em uma ideia kantiana de desenvolvimento que foi utilizada para endossar a filosofia moderna sobre a criança faltante. Para ele, o humano permanece inicialmente em uma menoridade que consiste em seguir os pensamentos e guiar suas condutas por outrem. O sentido de maioridade é pensado como uma capacidade de emancipação, cerne do movimento iluminista, ainda que tenha sido atribuído e utilizado com relação à criança (GRÓS, 2018).

xi Numa perspectiva foucaultiana, dispositivo possui uma "natureza essencialmente estratégica, um tipo de formação que em determinado momento histórico teve como função principal responder a uma urgência, e que supõe certa manipulação das relações de força, certa intervenção racional e organizada nestas relações de força" (VEIGA, 2002, p. 90).

xii Assujeitamento é colocado aqui enquanto um dos modos de produção de subjetividade, não enquanto uma passividade do sujeito produzido. Mais especificamente, enquanto estratégia de governo da infância e de produção dos corpos infantis, como apresentado por Oliveira (2016).

xiii Segundo Kastrup (2007), o regime atencional costuma cobrar por uma atenção seletiva, fixada em um ponto específico a ser observado com uma restrição sensorial. Nesse ponto, o hiperfoco significaria uma aproximação do sujeito com seu objeto atencional, do qual se consomem as imagens enquanto informações logo apreendidas e superadas, initerruptamente (LARROSA, 2002). Larrosa (2002) afirma esse sujeito como o da antiexperiência, já que devido sua superestimulação, não haveria tempo para a pausa, para o cultivo da atenção necessário na construção de um acontecimento, de uma experiência.

xiv Trata-se de um ponto de observação da cena em que se isola uma parte com o objetivo "de apresentar uma 'aproximação' no sentido próprio e figurado - que obedece a um desejo de entrar em intimidade maior com o personagem ou isolar um detalhe que importa na história” (JULLIER; MARIE, 2012, p. 24).

xv Sergio Carvalho (2009) assinala que nos constituímos sujeitos de direito imersos numa cidadania da sujeição a deveres instituídos.

xvi Que vem do exercício de uma atenção flutuante, não coincidindo com a dispersão atencional que naturalizamos nesse mundo abarrotado por informações a serem codificadas e que se tornam obsoletas num piscar de olhos (KASTRUP, 2007).

xvii Objeto-infância é colocado segundo a apropriação e criação que Heckert (2018) realiza. O objeto-infância é o modo pelo qual uma certa história tomou a infância como objeto de estudo, conhecimento e construiu saberes e práticas em cima dessa ideia particularizada que se tornou "verdadeira".

xviii Parafraseando o filme A culpa é de Fidel (2006), dirigido por Julie Gravas. 